\title{
A perceção dos stakeholders sobre o desenvolvimento turístico: o caso da Ilha de São Miguel, Açores
}

\author{
Fabiana Moniz* João Simão** \\ Universidade Aberta (Portugal)
}

\begin{abstract}
Resumo: O turismo na Região Autónoma dos Açores, e em especial na Ilha de São Miguel, tem sofrido nos últimos anos um aumento significativo que se repercute inevitavelmente em impactos económicos, socioculturais e ambientais. O planeamento estratégico da atividade torna-se ainda mais desafiante em territórios insulares de pequena dimensão. Neste contexto, o presente estudo tem como objetivos conhecer as perceções de diferentes stakeholders sobre os impactos do desenvolvimento turístico; a identificação dos principais motores impulsionadores/inibidores da competitividade do destino; e a caracterização da participação dos stakeholders locais no processo de planeamento. Metodologicamente optou-se por entrevistas semi-diretivas e análise de conteúdo a uma amostra de stakeholders de S. Miguel. Os resultados mostram que os impactos económicos positivos são os mais notados, como seria de esperar num destino em fase de crescimento, e um nível de participação pública ainda escasso.
\end{abstract}

Palavras-chave: Turismo; Impactos; Competitividade; Stakeholders; Participação; Açores.

Stakeholders's perception on tourism development: the case of the island of São Miguel, Azores

Abstract: Tourism in the Autonomous Region of the Azores, and especially in the island of São Miguel, has suffered in recent years a significant increase with repercussions on economic, socio-cultural and environmental impacts. Strategic planning of the activity becomes even more challenging in small island territories. In this context, the present study aims to know the perceptions of different stakeholders about the impacts of tourism development; the identification of the main drivers of the competitiveness of the destination; and the characterization of the level of involvement and participation of local stakeholders in the planning process. Methodologically, we chose semi-directive interviews and content analysis from a sample of stakeholders from the island of S. Miguel. The results show that the positive economic impacts are the most noticeable, as one would expect in a destination in the growth phase, and a level of public participation still scarce.

Keywords: Tourism, Impacts, Competitiveness, Stakeholders, Participation, Azores.

\section{Introdução}

A indústria do turismo representou à escala global, direta e indiretamente, em 2016, cerca de 10,2\% do Produto Interno Bruto mundial e estima-se que seja responsável por 292 milhões de empregos, o equivalente a 1 em cada 10 postos de trabalho (WTTC, 2017). Em Portugal, o turismo também apresenta-se como um dos principais setores da economia, possuindo uma grande importância para $o$ emprego e para o crescimento das exportações (Turismo de Portugal I.P., 2017).

À semelhança do panorama nacional, o turismo tem-se revelado cada vez mais importante para o desenvolvimento económico da Região Autónoma dos Açores (RAA), assistindo-se desde abril de 2015 a um crescimento acentuado do setor. A região insular combina um leque variado de valores naturais únicos (como sejam espécies endêmicas de fauna e flora, vistas panorâmicas, lagoas, montanhas, quedas de água, fontes termais) que a transforma num destino apetecível e exótico para o ecoturismo. A realização

\footnotetext{
* Universidade Aberta (Portugal); E-mail: fabianamoniz5@gmail.com

**Universidade Aberta (Portugqal); E-mail: joao.simao@uab.pt
} 
de atividades ao ar livre, em terra e, principalmente, no mar (observação de baleias e golfinhos, snorkel e mergulho) constituem as atrações turísticas mais populares nas ilhas.

Todavia, para além dos evidentes benefícios económicos, o crescente desenvolvimento da atividade turística pode acarretar um leque variado de constrangimentos e de impactos negativos à comunidade local, nos domínios ambiental, social, cultural e económico. Esta dualidade conduz, inevitavelmente, ao surgimento de preocupações para com a necessidade de mitigação dos impactos negativos, assim como para a potencialização dos impactos positivos e das vantagens competitivas do destino turístico. O desenvolvimento turístico pretende-se que seja sustentável, com a participação ativa dos agentes interessados. Os stakeholders desempenham um papel de extrema importância em qualquer processo de planeamento político, económico, ambiental e sociocultural no contexto da realidade em que se encontram inseridos.

A auscultação destes atores assume-se como uma etapa crucial para um melhor entendimento das necessidades efetivas e para a tomada de ações no sentido de as colmatar (Simão \& Partidário, 2012). O envolvimento de múltiplos stakeholders no planeamento, pode facilitar a integração e resolução de várias questões sociais, culturais, ambientais, económicas e políticas relevantes no desenvolvimento sustentável (Bramwell \& Lane, 2000) e explicitar as necessidades e expetativas da sociedade (Caffyn \& Jobbins, 2003) através de um processo mais eficiente, equitativo e harmonioso (Timothy, 1998).

Assim, tendo em consideração o recente crescimento do setor do turismo e a sua importância na RAA e principalmente na Ilha de São Miguel, este trabalho tem como objetivos: (i) Caracterizar a perceção dos diversos stakeholders sobre os impactos económicos, sociais e ambientais; ii) Identificar, segundo o Modelo de Competitividade dos Destinos Turísticos (Ritchie \& Crouch, 2000, 2003), as potencialidades e os constrangimentos do destino 'São Miguel'; (iii) Caracterizar o envolvimento e a participação dos stakeholders no processo de planeamento do turismo da ilha.

Para alcance destes objetivos foram realizadas entrevistas a uma amostra de stakeholders representativos de ONG's Ambientais; Administração e Agências do Governo Regional; Associações Culturais; Especialistas e Investigadores em Turismo e Associações de Empresários, Indústria e Comércio.

O artigo está organizado do seguinte modo. As secções 2 e 3 incidem na revisão da literatura sobre o turismo em espaços insulares e no planeamento da atividade, com destaque para o modelo da competitividade dos destinos turísticos de Ritchie e Crouch $(2000,2003)$ e para a necessidade de envolvimento da comunidade e dos stakeholders. A secção 4 faz uma breve caraterização do arquipélago dos Açores. A metodologia é o tema da secção 5. Os resultados e a discussão estão presentes na secção 6. Finalmente, apura-se as principais conclusões.

\section{Turismo em espaços insulares}

Os espaços insulares são, na maioria das vezes, vistos como espaços idílicos, isolados e únicos, cada vez mais, procurados como destinos para "fuga" do stress quotidiano das grandes cidades, oferecendo experiências culturais e naturais autênticas, em antítese à vida urbanizada quotidiana (Carlsen \& Butler, 2011). O isolamento, frequentemente visto como uma desvantagem económica, tende a ser valorizado em termos turísticos, tornando o destino mais exótico e apetecível aos olhos do turista, principalmente no caso das ilhas de pequena dimensão (Scheyvens \& Momsen, 2008). No Mediterrâneo, Caribe e Pacifico $\mathrm{Sul}$ situam-se as ilhas que constituem os principais destinos turísticos, sendo também de registar um incremento da atividade nas ilhas do Atlântico e do Oceano Índico (Carlsen \& Butler, 2011).

Os territórios insulares possuem constrangimentos comuns resultado da sua reduzida dimensão, nomeadamente dispersão territorial e limitação de recursos e acessibilidades, com repercussão direta na economia e na sociedade (Silva, 2013). São também espaços mais vulneráveis a determinadas ameaças ambientais: variabilidade climática, proliferação de espécies invasoras, catástrofes naturais e exploração de recursos naturais (Rietbergen et al., 2007). Características que colocam às ilhas autênticos desafios no que diz respeito ao planeamento e ao desenvolvimento turístico sustentável (Sharpley, 2012; Calado et al., 2007; Sheldon, 2005). Contudo, estes territórios têm tentado afirmar-se como destinos turísticos, esforçando-se por mitigar as suas debilidades económicas (Silva \& Umbelino, 2017) e usufruir dos benefícios produzidos pelo setor. Segundo Croes (2006), para além dos contributos diretos do turismo para o emprego e a economia local, a aposta no turismo apresenta consideráveis vantagens para as economias insulares de pequena dimensão, traduzidas no aumento da procura de bens e serviços, que possibilita a viabilidade de diversos produtos e a redução de custos de produção; a abertura ao exterior e o incremento da concorrência conduzem ao aumento da eficiência e da qualidade, enquanto que a 
melhoria dos padrões dos serviços locais e os contributos indiretos do turismo estimulam outros setores da economia local.

Muitos dos impactos do turismo em espaços insulares são materialmente idênticos aos que ocorrem noutros espaços (veja-se p.e. Wall e Mathieson, 2006, para um desenvolvimento acerca do tema dos impactos) mas, por estarmos perante territórios isolados e de reduzida dimensão, assumem uma proporção superior. Na tabela 1 identifica-se alguns dos impactos mais referidos na literatura.

Tabela 1: Impactos da atividade turística em espaços insulares mais comuns na literatura

\begin{tabular}{|c|c|c|}
\hline & Impactos positivos & Impactos negativos \\
\hline 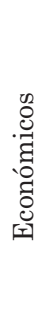 & $\begin{array}{l}\text { Crescimento das receitas (diretas e } \\
\text { indiretas); } \\
\text { Geração de emprego; } \\
\text { Diversificação da economia (num } \\
\text { estado inicial); } \\
\text { Melhoria das infra-estruturas físicas }\end{array}$ & $\begin{array}{l}\text { Monocultura (a partir de determinada fase); } \\
\text { Dependência económica de operadores turísticos externos- } \\
\text { colonialismo económico; } \\
\text { Emprego sazonal, de baixa qualificação e mal remunerado. } \\
\text { Parte do emprego qualificado vem do exterior; } \\
\text { Inflação de diversos bens, terrenos (acompanhado de } \\
\text { especulação) e habitação; } \\
\text { Elevadas fugas económicas; } \\
\text { Competição por recursos escassos; } \\
\text { Competição por infra-estrutras (saúde, localização) }\end{array}$ \\
\hline 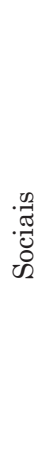 & $\begin{array}{l}\text { Interesse e revitalização das artes, } \\
\text { artesanato e culturas locais (história, } \\
\text { língua, arquitetura, religião, trajes, } \\
\text { gastronomia) }\end{array}$ & $\begin{array}{l}\text { Aumento de stress; } \\
\text { Efeitos de demonstração, mimitização da cultura dos } \\
\text { visitantes, com redução da autenticidade da cultura e } \\
\text { património local; } \\
\text { Alterações nos modos de vida familiares; } \\
\text { Valorização da cultura dos visitantes (moderna) em } \\
\text { detrimento da local (ultrapassada e fora de moda) } \\
\text { - sobretudo percecionado pelos jovens; } \\
\text { Aumento do custo de vida; } \\
\text { Comercialização da história, das tradições culturais e das } \\
\text { relações humanas; } \\
\text { Aumento da criminalidade, vandalismo, prostituição e jogo; } \\
\text { Excesso de trabalho no período sazonal com impactos na } \\
\text { vida familiar, cultural e religiosa }\end{array}$ \\
\hline 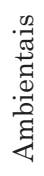 & $\begin{array}{l}\text { Incentivo à preservação e } \\
\text { requalificação ambiental (incluindo a } \\
\text { criação de parques naturais); }\end{array}$ & $\begin{array}{l}\text { Poluição; } \\
\text { Mais lixo; } \\
\text { Congestionamento, tráfego; } \\
\text { Destruição de floresta nativa, perda de flora e fauna, } \\
\text { devido à construção de infra-estruturas, e trilhos }\end{array}$ \\
\hline
\end{tabular}

A melhor forma de reforçar os impactes positivos e de mitigar os impactes negativos, evitando a degradação social e ambiental do destino, é recorrendo ao planeamento. Sem planeamento existe o risco da atividade turística ficar desregulada, desordenada e ineficiente (Mason, 2003) conduzindo à delapidação do capital físico e social de que dependem os ecossistemas e a comunidade local. Neste âmbito, a competitividade dos destinos e um planeamento que envolva os stakeholders, são os temas abordados na próxima secção.

\section{Destinos turisticos: stakeholders e competitividade}

Embora o conceito de stakeholder remonte à década de 60 do século XX, foi após a década de 80 que ganhou relevância e difusão sendo definido como qualquer indivíduo ou grupo que pode afetar o desempenho da organização, ou ser afetado pelos objetivos desta (Freeman, 1984). Apesar de originalmente a teoria dos stakeholders ser aplicada à gestão estratégica das organizações, o conceito difundiu-se ao turismo no âmbito organizacional (Céspedes-Lorente et al., 2003, p.e.) e no planeamento e gestão 
das áreas de destino (Araujo \& Bramwell, 1999; p.e.). Também ao nível institucional a envolvência de todos os atores chave é encarado como um princípio básico para a implementação da sustentabilidade.

Uma das áreas prioritárias definidas na Agenda 21 para a indústria de viagens e turismo (WTTC et al., 1993) consiste precisamente na promoção e participação de todos os sectores da sociedade. A literatura tem identificado diversos stakeholders fundamentais no planeamento turístico. De entre os mais mencionados constam a comunidade local, a indústria, o sector público, os grupos ativistas e os turistas, ao que Sautter e Leisen (1999) acrescentam os trabalhadores e os competidores, e Swarbrooke (1999) introduz os media. A WTO no trabalho Sustainable Tourism Development: Guide for Local Planners (1993) agrega os principais parceiros para o desenvolvimento turístico sustentável em três grandes grupos que vão ao encontro das dimensões da sustentabilidade: indústria, associações de defesa do ambiente e comunidade local, esta composta por residentes, governo local, associações de comércio local e outras instituições e associações locais.

O objetivo último da gestão de um destino turístico é contribuir para a prosperidade dos stakeholders (com ênfase na comunidade local). A forma como os destinos turísticos mantêm, protegem e fortalecem a sua posição de competitividade num mercado cada vez mais exigente é um dos desafios mais determinantes e importantes para a indústria do turismo (Crouch, 2007), na medida em que o desenvolvimento do potencial turístico de um destino depende da sua capacidade em manter a vantagem competitiva no fornecimento de bens e serviços aos turistas.

Para Ritchie e Crouch (2000:306), a competitividade é a "capacidade de agregar valor e, assim aumentar a riqueza pela gestão de bens e processos através da integração dessas relações dentro de um modelo económico e social que leva em consideração o capital natural do destino e a sua preservação para as futuras gerações". Estes autores propõem um modelo de análise de competitividade de um destino turístico. De acordo com este modelo, a competitividade surge como resultado da relação de cinco grupos de fatores, que influenciados por agentes macro e microambientais, resultam em vantagens competitivas e comparativas de um destino turístico. Estes fatores são descritos por Crouch e Ritchie (1999) da seguinte forma:

1) Recursos Centrais e Atrativos - são os elementos primários da atratividade de um destino, representando os aspetos centrais da motivação do visitante. Incluem os seguintes componentes: aspetos naturais, culturais e históricos, elos (culturais, étnicos e históricos) com mercados emissores, conjunto de atividades oferecidas, eventos especiais e estrutura turística (acomodação, serviços de alimentação, transporte e outros atrativos).

2) Política, Planeamento e Desenvolvimento do Destino - são fatores relacionados como a definição do sistema, a filosofia, auditoria, posicionamento, monitorização e avaliação, entre outros -, com objetivos económicos sociais e outros, permitem uma orientação para a direção, forma e estrutura do desenvolvimento turístico.

3) Fatores de Suporte e Recursos - fatores de apoio para o desenvolvimento do destino turístico, incluindo recursos como: infraestruturas (serviços de transporte locais, saneamento básico, abastecimento de água, sistemas de comunicações, etc...), acessibilidades (regulamentação da aviação civil; vistos de entrada e permanência; capacidade aeroportuária, etc...), serviços e recursos facilitadores (instituições financeiras, recursos humanos, conhecimento, capital, etc...) suporte político que fomente o apoio ao desenvolvimento turístico.

4) Gestão do Destino - atividades que fomentam a atratividade dos recursos centrais e aumentam a qualidade dos Fatores de Suporte e adaptam o destino às restrições dos Determinantes Qualificadores. Inclui os seguintes componentes: marketing, organização do destino, manutenção da qualidade dos serviços, sistemas de informação e manutenção dos atrativos do destino.

5) Determinantes Qualificadores - condições situacionais que afetam a competitividade do destino, como: localização, dependência de outros destinos, segurança e custo.

Assim, é possível deduzir que o sucesso e a manutenção competitiva no mercado global está intrinsecamente depende dos recursos básicos do destino aliados a uma gestão, organização e monitorização direcionadas para o crescimento económico e competitivo (Crouch \& Ritchie, 1999).

\section{Breve caraterização local}

São Miguel faz parte do conjunto de 9 ilhas de origem vulcânica que compõem o Arquipélago dos Açores. Localizada no Oceano Atlântico, dista a cerca de $1.570 \mathrm{~km}$ de Portugal Continental e a 3.900 km da costa ocidental da América do Norte. 


\section{Figura 1: Arquipélago dos Açores}
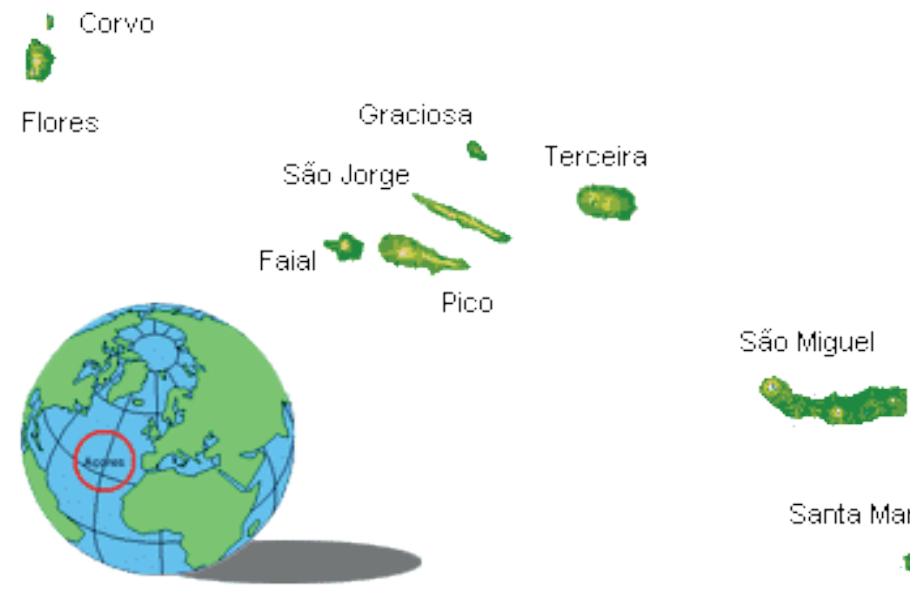

Santa Maria

Extraído de http://www.azores.gov.pt

Numa pequena economia, como a da RAA, o processo de crescimento e desenvolvimento económico necessita de passar pela produção de bens e serviços virados para a exportação (Observatório do Turismo dos Açores, 2008). Assim, e tendo em consideração as características naturais dos Açores, bem como a expansão da procura global, o turismo é considerado um setor promissor, fazendo parte de um número limitado de oportunidades capazes de ampliar e diversificar a base económica de exportação da Região (Santos et al., 2012).

Os Açores possuem, para além da abundância e diversidade dos recursos naturais endógenos, uma extensa zona económica exclusiva marítima de $984.300 \mathrm{~km}^{2}$, que possibilita e potencia a oferta de produtos temáticos ligados à natureza, ao vulcanismo, ao espaço rural e ao mar, bem como a riqueza do seu património histórico, arquitetónico e cultural, que fazem com que o turismo tenha vindo a emergir como uma alternativa estratégica para o desenvolvimento do arquipélago (Moniz, 2006).

Desde 2015, com a abertura de parte do espaço aéreo dos Açores às companhias aéreas de baixo custo, oferecendo ligações da Ilha de São Miguel para o Continente e para Londres, e da Ilha Terceira para Lisboa e Porto, em conjunto com a aplicação de uma política de reencaminhamento gratuito para outras ilhas do arquipélago, verificou-se um incremento da concorrência com repercussão muito significativa no número de turistas na RAA (Silva \& Umbelino, 2017).

No que se refere ao caso específico de São Miguel, é possível verificar que esta ilha apresenta uma expressiva representatividade no turismo regional, detendo mais de $50 \%$ da capacidade de alojamento e mais de $60 \%$ dos proveitos totais decorrentes do setor de atividade na RAA.

\section{Metodologia}

A maioria dos estudos direcionados para a análise das perceções sobre os impactos provocados pelo turismo optam pela metodologia quantitativa (veja-se o levantamento feito por Sharpley, 2014). Alguns dos exemplos mais recentes são Simão e Môsso (2013), Sánchez-Cañizares et al. (2016), Muresan et al. (2016), Almeida-García et al. (2016), Rasoolimanesh et al. (2017), Zhu et al. (2017), Campón-Cerro et al. (2017), Liu \& Li (2018), Eusébio et al. (2018), Harun et al., (2018), Chang et al. (2018). Porém, este estudo, à semelhança de alguns em menor número (Özel \& Kozak, 2017, Wright \& Sharpley, 2018, Woosnam et al, 2018, p.e.), recorrerá ao método qualitativo.

A opção por uma metodologia qualitativa foi realizada em virtude da profundidade das informações que se pretendia obter, tentando conhecer fundamentadamente as posições dos stakeholders face às mudanças ocasionadas pelo crescimento do turismo, o que tornou a entrevista semi-diretiva o método de recolha de dados mais adequado para o desenvolvimento da pesquisa. Este método possibilita obter informações com um grau mais elevado de profundidade acerca do tema abordado, para além de permitir recolher os testemunhos e as interpretações dos entrevistados, respeitando os seus próprios quadros de referência (linguagem e suas categorias mentais) (Quivy \& Campenhoudt, 1995). 
No presente estudo as entrevistas foram compostas por perguntas abertas, tendo sido efetuadas presencialmente a uma amostra de stakeholders localizados em São Miguel durante o segundo semestre de 2016. A amostra em número de 10 foi definida com enfoque em stakeholders que se fazem representar, com maior frequência, em processos de participação pública no âmbito do setor turístico: ONG's Ambientais (2); Administração e Agências do Governo Regional (2); Associações Culturais (1); Especialistas e Investigadores em Turismo (3) e Associações de Empresários da Indústria e Comércio (2), o que vai ao encontro do conjunto de stakeholders institucionais identificados na Secção 3. Por a ilha ter dimensão reduzida, um número acrescido de entrevistas não iria aumentar o tipo de instituições representadas no estudo, mas apenas aumentar o número de entrevistados por instituição.

O teor das entrevistas foi sujeito a análise de conteúdo, um dos procedimentos clássicos para analisar texto, com vista a reduzir o material textual a categorias (Flick, 2014), num processo progressivo de leitura e de anotação do material.

\section{Resultados}

A organização deste ponto está de acordo com os principais objetivos de investigação traçados: perceção de impactos, fatores impulsionadores e entraves à competitividade e participação dos stakeholders.

a) Perceção dos impactos positivos e negativos do desenvolvimento turístico na Ilha de São Miguel.

Estando o turismo numa fase de grande expansão em São Miguel, tornou-se importante perceber qual a visão atual dos stakeholders face a este desenvolvimento, aos seus benefícios e constrangimentos gerados e à forma como o turismo tem sido gerido na região, por forma a potenciar as suas vantagens e minimizar as suas fraquezas.

No que respeita à perceção dos impactos económicos foi possível concluir que estes são, maioritariamente, entendidos como consequências positivas e benéficas para os stakeholders micaelenses, na medida em que proporcionaram um incremento e uma diversificação da economia local, gerando emprego num cenário de pouca empregabilidade.

“(...) todo este movimento trouxe novas oportunidades de emprego e de investimento.”(E2)

\section{“(...) aumento do emprego e dinamização da economia da região.”(E10)}

Para além do aumento do emprego, são também identificados como benefícios para a população micaelense, a diversificação da economia, o surgimento de investimentos externos devido à projeção internacional do destino Açores, a estabilização dos mercados e de pequenos negócios.

"Diversificou a economia, gerou a própria diversificação do modelo turístico, gerou ganhos monetários, mas, também, projeção internacional e atraiu investidores externos". (E6)

Estas conclusões vão de encontro aos estudos de Andriotis (2001), Ivanov e Webster (2007), Liu e Var (1986) e Haralambopoulos e Pizam (1996) que notaram que os impactos económicos do turismo são percecionados pelas populações, como positivos. Para estes o turismo ajuda a economia, aumenta o padrão de vida das comunidades residentes, gera emprego e aumenta o lucro dos negócios locais.

Relativamente aos impactos negativos do turismo, no domínio económico, a maioria dos entrevistados não identifica malefícios muito significativos nesta fase de crescimento turístico. Todavia, alguns identificam um aumento dos preços dos imóveis e de alguns serviços e bens de consumo, o que converge com Liu e Var (1986), por exemplo, onde se salienta que o desenvolvimento turístico pode conduzir a um agravamento do custo de vida, caracterizado pelo aumento dos serviços, bens alimentares, imobiliário e terrenos.

“o aumento da procura turística já se está a sentir, por exemplo, no aumento de preços”. (E7)

"Talvez um ligeiro aumento dos preços dos imóveis e de alguns serviços.”(E10) 
Ambientalmente, o aumento do fluxo de visitantes tem provocado um acúmulo de resíduos, a degradação de trilhos pedestres e a existência de uma sensação de "crowding" em áreas sensíveis, principalmente no ramo das atividades marítimo-turísticas.

"Nos trilhos existe uma sobrecarga, trilhos degradados por sobreuso e pela visitação desordenada (...)."(E6)

\section{(...) aumento do crowding (...) nas atividades marítimo-turísticas (...)..”(E7)}

Contudo, de acordo com a informação obtida e corroborando Kim (2002), o turismo também tem vindo a proporcionar a criação de uma maior consciência para a necessidade de preservar o meio ambiente, e um maior cuidado e limpeza dos locais, na tentativa de mostrar ao visitante a melhor imagem da região.

“(...) uma maior consciência e preservação do nosso património (...).”(E9)

“(...) existência de um reforço da preservação ambiental, conservação da nossa natureza (...)”(E10)

Em matéria sociocultural, os benefícios mais percecionados recaem no aparecimento de uma oferta mais diversificada de atividades culturais, em quantidade e qualidade, na dinamização do artesanato, no enriquecimento cultural da população local através do contacto com outras culturas e uma certa recuperação da identidade cultural açoriana, assim como um aumento do orgulho pela cultura e pelas tradições locais. Estes fatores já tinham sido evidenciados por Guo et al., (2014), McDowall e Choi (2010) e Liu e Var (1986).

“(...) uma oferta mais diversificada e mais cuidada de atividades (...).”(E1)

(...) permitiu aos micaelenses encontrarem um pouco das raízes da sua identidade cultural (...)”(E5)

“(...) reavivar de algumas tradições e manifestações culturais, muitas vezes esquecidas, por forma de dar a conhecer aos visitantes a nossa cultura." (E10)

Alguns dos entrevistados denotam a presença de impactos negativos no congestionamento e sobrelotação, traduzida em dificuldade de acesso por parte da comunidade micaelense a determinados lugares, que antes eram muito fáceis de aceder; assim como um aumento do lixo e do barulho no centro urbano (Ponta Delgada).

“(...) talvez uma sobrecarga de locais, que do ponto de vista social ficam um pouco condicionados, não podendo, muitas das vezes, nós enquanto habitantes desfrutar (...)” (E1)

“(...) acúmulo de lixo e ruido excessivo no centro urbano”. (E7)

Foi notada também a existência de um certo choque de mentalidades (a que Dogan (1989) aluía), a descaracterização de manifestações ou expressões culturais (à semelhança do evidenciado por McDowall e Choi, 2010) e alguma mudança no estilo de vida familiar e social, em consequência das novas exigências do mercado de trabalho voltado para o turismo.

"Talvez alguns choques de mentalidades possam ter ferido suscetibilidades (...).”(E5),

“(...) poderá assistir se a uma descaracterização de algumas manifestações ou expressões populares.”(E6),

“(...) setor que, por norma, paga mal e que obriga a trabalhar por turnos, fora dos horários, normalmente, aceites pelo povo português (...).” (E8)

Contrariamente ao que seria esperado, não é associado ao turismo um aumento da taxa de criminalidade, de alcoolismo, do consumo de drogas e da prostituição conforme tantas vezes referenciado na literatura (Mason, 2003, p.e.).

A Tabela 2 resume os impactos referidos. 


\section{Tabela 2: Impactos do turismo percecionados na ilha de São Miguel}

\begin{tabular}{|c|c|c|}
\hline $\begin{array}{l}\text { Tipo de } \\
\text { Impacto }\end{array}$ & Positivo & Negativo \\
\hline Económicos & $\begin{array}{l}\checkmark \text { Novas oportunidades de emprego e } \\
\text { investimento interno e externo; } \\
\checkmark \text { Aumento da receita; } \\
\checkmark \text { Crescimento de setores (comércio, } \\
\text { hotelaria, restauração, artesanato); } \\
\checkmark \text { Diversificação da economia; } \\
\checkmark \text { Projeção internacional; } \\
\checkmark \text { Estabilização de mercados e de } \\
\text { empresas; } \\
\checkmark \text { Rentabilização das infraestruturas } \\
\text { hoteleiras existentes. }\end{array}$ & $\begin{array}{l}\checkmark \text { Aumento significativo dos preços dos } \\
\text { imóveis e de alguns serviços; } \\
\checkmark \text { Diminuição de verbas para } \\
\text { investimento nos restantes setores de } \\
\text { atividade. }\end{array}$ \\
\hline Ambientais & $\begin{array}{l}\checkmark \text { Maior preocupação com a apresentação } \\
\text { dos locais que conduz a um maior } \\
\text { cuidado e limpeza dos mesmos; } \\
\checkmark \text { Mudança de comportamento na } \\
\text { comunidade local, de preservação da } \\
\text { paisagem, na tentativa de mostrar a } \\
\text { melhor imagem da região ao visitante; } \\
\checkmark \text { Reforço da conservação ambiental; } \\
\checkmark \text { Aumento da angariação de verbas para } \\
\text { a manutenção e limpeza. }\end{array}$ & $\begin{array}{l}\checkmark \text { Sobrecarga de alguns locais que pode } \\
\text { conduzir a algum detrimento da sua } \\
\text { qualidade ambiental; } \\
\checkmark \text { Sensação de "crowding" em áreas } \\
\text { sensíveis, principalmente, no ramo } \\
\text { das marítimo-turísticas; } \\
\checkmark \text { Acumulo de Resíduos devido a falha } \\
\text { na rede de caixotes, separadores, } \\
\text { recolha, etc; } \\
\checkmark \text { Trilhos degradados devido à } \\
\text { sobrecarga e visitação desordenada. }\end{array}$ \\
\hline Socioculturais & $\begin{array}{l}\checkmark \text { Oferta mais diversificada de atividades } \\
\text { culturais, não só no aumento do número } \\
\text { de eventos, mas também na qualidade } \\
\text { dos mesmos; } \\
\checkmark \text { Surgimento de novas oportunidades } \\
\text { de emprego para profissionais } \\
\text { especializados; } \\
\checkmark \text { Recuperação da identidade cultural; } \\
\checkmark \text { Enriquecimento cultural através do } \\
\text { contacto com outras culturais; } \\
\checkmark \text { Aumento do orgulho pela cultura local. }\end{array}$ & $\begin{array}{l}\checkmark \text { Condicionamento e sobrelotação de } \\
\text { alguns locais; } \\
\checkmark \text { Choque de mentalidades; } \\
\checkmark \text { Descaracterização de algumas } \\
\text { manifestações ou expressões } \\
\text { populares; } \\
\checkmark \text { Aumento do barulho no centro urbano } \\
\text { de Ponta Delgada; } \\
\checkmark \text { Mudanças no estilo de vida familiar } \\
\text { e social, em consequência das novas } \\
\text { exigências do mercado de trabalho, } \\
\text { vocacionado para o turismo. }\end{array}$ \\
\hline
\end{tabular}

b) Elementos impulsionadores e principais entraves à competitividade do destino turístico de São Miguel

Sendo o mercado turístico caracterizado pela constante mudança e elevada concorrência, tentou-se apurar junto dos representantes dos stakeholders quais as fraquezas e vantagens competitivas que São Miguel possui face a outros destinos turísticos, segundo o Modelo de Competitividade desenvolvido por Ritchie e Crouch (2000, 2003).

Segundo a análise das entrevistas, foi possível apurar que as dimensões que os entrevistados mais identificaram como potenciadoras da competitividade de São Miguel, foram os Recursos Centrais e Atrações e os Determinantes Qualitativos.

Nos Recursos Centrais e Atrações foram destacados como elementos fundamentais: a cultura, o clima, a qualidade ambiental, a gastronomia, a diversidade paisagística, o Termalismo e a biodiversidade terrestre e marinha. Enquanto nos Determinantes Qualitativos foi evidenciada a segurança e a tranquilidade.

Os resultados alcançados contrapõem-se ao estudo realizado por Goffi (2013) em vários destinos turísticos italianos, onde stakeholders evidenciam como os maiores determinantes da competitividade turística a gestão do destino e a política, planeamento e desenvolvimento do destino. Esta situação talvez se justifique pelo facto da RAA ser conhecida internacionalmente pela imagem de turismo de natureza e de mar, com grande enfoque nos recursos naturais.

Para potenciar os fatores competitivos de São Miguel, os entrevistados apontaram algumas medidas/ ações que deveriam ser tomadas, sendo estas: a melhoria da rede de transportes; a realização de uma 
gestão mais eficiente, para não ultrapassar a capacidade de carga; o ajuste da imagem promocional da região aos recursos existentes - marketing; mais investimento na preservação dos recursos naturais e na gestão das áreas protegidas; mais divulgação da gastronomia local e continuar a perpetuar a imagem de sustentabilidade da região (Tabela 3).

\section{Tabela 3: Fatores determinantes e proposta de medidas potenciadoras para o turismo em S. Miguel}

\begin{tabular}{|l|l|}
\hline \multicolumn{2}{|c|}{ Fatores Determinantes } \\
\hline$\checkmark$ Diversidade paisagística - Recurso central & $\checkmark$ Ajustar a imagem da região aos recursos existentes; \\
e Atrativo; & $\checkmark$ Melhorar e assegurar mais transportes; \\
$\checkmark$ Biodiversidade Terrestre e Marinha- & $\checkmark$ Promoção dos açores como um arquipélago \\
Recurso central e Atrativo; & diversificado, com características únicas e experiências \\
$\checkmark$ Qualidade Ambiental- Recurso central e & $\checkmark$ diversificadas em todas as ilhas; \\
Atrativo; & $\checkmark$ Dar mais importância às Áreas Protegidas; \\
$\checkmark$ Infraestruturas - Recurso central e & $\checkmark$ Gestão mais eficiente, por forma a evitar a rutura ou \\
Atrativo; & ultrapassar a capacidade de carga; \\
$\checkmark$ Divulgação e marketing - Gestão do & $\checkmark$ Gestão efetiva dos recursos naturais e das Áreas \\
Desenvolvimento; & Protegidas; \\
$\checkmark$ Termalismo - Recurso central e Atrativo; & $\checkmark$ Melhorar o marketing e a promoção do produto \\
$\checkmark$ Segurança e Tranquilidade- Recursos & "Açores"; \\
Qualificadores; & $\checkmark$ Investir cada vez mais na preservação dos recursos \\
$\checkmark$ Cultura - Recurso central e Atrativo; & naturais; \\
$\checkmark$ Clima - Recurso central e Atrativo; & $\checkmark$ Mais divulgação da gastronomia; \\
$\checkmark$ Gastronomia - Recurso central e Atrativo. & $\checkmark$ Continuar a perpetuar a imagem de sustentabilidade. \\
\hline
\end{tabular}

No tocante às principais fraquezas (Tabela 4), foram identificados as dimensões 'política', 'planeamento' e 'desenvolvimento' do destino, da gestão do destino e dos recursos centrais e atrações. Ao nível da política, planeamento e desenvolvimento, estas fraquezas são baseadas no desconhecimento da capacidade de carga e na falta de liderança política. Na gestão do destino é evidenciada a falta de formação dos profissionais e a dificuldade em atrair investidores externos. Por sua vez, nos recursos centrais e atrações recai a apreensão sobre a instabilidade climática e recursos limitados e sensíveis à pressão humana.

Para além destas dimensões, também, foram mencionadas fraquezas nos determinantes qualitativos e amplificadores em virtude da localização do arquipélago.

Estas fraquezas vão ao encontro do estudo de Oliveira e Sá (2014), onde é destacado como pontos mais fracos da competitividade da cidade do Porto a gestão do destino, na qual é evidenciada, entre outros fatores: a falta de formação dos recursos humanos; a falta de interação, planificação, coordenação e comunicação entre os agentes do turismo e o excesso de burocracia. Este aspeto leva-nos a interrogar se não estaremos perante uma situação que é comum na generalidade do território português.

\section{Tabela 4: Potenciais fraquezas e proposta de medidas mitigadoras no turismo em S. Miguel}

\begin{tabular}{|l|l|}
\hline \multicolumn{1}{|c|}{ Fraquezas } & \multicolumn{1}{c|}{ Mitigar } \\
\hline$\checkmark$ Distância; & $\checkmark$ Apostar no desenvolvimento de atividades turísticas (culturais) que \\
$\checkmark$ Instabilidade climática; & não estejam dependentes do tempo (atividades em espaços fechados); \\
$\checkmark$ Acessibilidades; & $\checkmark$ Atrair investidores vocacionados para o turismo de natureza; \\
$\checkmark$ A formação dos profissionais na & $\checkmark$ Mais abertura da comunidade para os turistas \\
área do turismo; & $\checkmark$ Desburocratização dos processos de investimento; \\
$\checkmark$ Desconhecimento da & $\checkmark$ Mais investimento nos serviços do setor; \\
capacidade de carga; & $\checkmark$ Apostar na formação dos profissionais do setor; \\
$\checkmark$ Falta de liderança política; & $\checkmark$ Renovação dos quadros de representação politica; \\
$\checkmark$ Recursos limitados e sensíveis & $\checkmark$ Melhoria contínua da oferta de serviços; \\
à pressão humana. & $\checkmark$ Mais investimento por parte das próprias empresas na formação \\
\hline
\end{tabular}


Com a finalidade de mitigar estas fraquezas os stakeholders argumentam que deve existir: uma aposta no desenvolvimento de atividades turísticas, principalmente culturais, que não estejam dependentes do estado do tempo; maior promoção para atração de investidores vocacionados para o turismo de natureza; desburocratização dos processos de investimento; mais abertura da comunidade para os turistas; aposta na formação dos profissionais e mais investimento nos serviços do setor; substituição de líderes políticos; melhoria contínua da oferta de serviços e mais investimento por parte das próprias empresas na formação dos seus funcionários.

c) Envolvimento e de participação dos stakeholders no processo de planeamento do turismo da Ilha de São Miguel.

Apesar dos entrevistados atribuírem importância à necessidade da participação ativa de todos os agentes locais no processo de decisão, foi possível apurar que o envolvimento dos stakeholders locais é realizado de forma bastante residual, predominantemente através de uma Participação Passiva, caracterizada por os stakeholders apenas tomarem conhecimento das ações a tomar ou já tomadas. O feedback dos stakeholders é mínimo ou mesmo inexistente e a sua participação é contabilizada apenas como um número no processo de participação (Tufte \& Mefalopulos, 2009). Já de acordo com a escada da participação pública de Arnstein (1969), o nível de participação dos stakeholders locais pode caracterizar-se por uma mistura da fase da Informação e da Consulta, onde as pessoas até têm conhecimento dos seus direitos e responsabilidades, mas a informação, normalmente, só é realizada num fluxo de cima para baixo.

“(...) estes planos têm (...) um período de participação, pois a lei, também o obriga (...) ou seja, existe participação (...), se ela é eficaz e reprodutiva nas decisões não posso afirmar.”(E1)

"Acho que não, penso que está cada um no seu canto, a tentar fazer o seu negocio (...)”. (E8)

De acordo com os entrevistados, esta situação surge em virtude de uma certa dificuldade dos stakeholders e decisores políticos trabalharem em equipa, a alguma falta de interesse por parte das entidades em promover e incentivar a participação dos diversos agentes locais, não atribuindo grande importância a este processo.

"Porque em São Miguel não há essa tradição e porque os decisores não veem a sua necessidade."(E6)

“(...) nós não sabemos trabalhar em conjunto e é difícil conseguir juntar esforços, juntar stakeholders para o fazer." (E8)

Estas limitações fazem parte do que Tosun (2000) designou por limitações operacionais, caracterizadas pela centralização da administração pública do turismo, falta de coordenação e falta de informação e por limitações estruturais, que englobam a atitude dos profissionais; a dominação da elite; a falta de um sistema legal apropriado; a falta de formação dos recursos humanos; custos relativamente elevados associados à participação pública e a falta de recursos financeiros.

Quanto à importância deste processo participativo, os entrevistados alegam que o envolvimento dos agentes interessados seria uma mais-valia e desempenharia um papel crucial para definição de medidas adaptadas à realidade e às necessidades efetivas do setor e da região, o que reforça o pensamento de Bramwell e Lane (2000), Caffyn e Jobbins, (2003) e Timothy (1998). O envolvimento de múltiplos stakeholders no planeamento pode facilitar a integração e resolução de várias questões sociais, culturais, ambientais, económicas e políticas relevantes no desenvolvimento sustentável e beneficiar a compreensão das necessidades e expetativas da sociedade através de um processo mais eficiente, equitativo e harmonioso.

"Sim, é muito importante. Se não formos envolvidos na participação e se ela não existir certamente que não irá resultar em nada positivo." (E1)

"Sim, claro que a participação seria extremamente importante, pois só através da auscultação é que é possível alcançar a definição de estratégias eficazes e adaptadas à realidade." (E7) 
Quando questionados sobre como a participação deveria ser melhorada, os entrevistados acham que deveria: existir um conselho alargado representativo de todos os agentes para o turismo, semelhante ao existente para outros setores de atividade; maior divulgação e discussão dos resultados alcançados; mais auscultação e integração dos contributos das diversas entidades; mais entendimento entre os diversos stakeholders; existência de fóruns e eventos com os diversos stakeholders; e atribuição de benefícios que favoreçam a participação.

"A eventual existência dum conselho mais alargado, como é o caso do conselho regional da agricultura, onde possam estar, efetivamente, os diversos setores representados." (E1)

Simultaneamente com a análise do tipo de participação pública existente em São Miguel, foi possível aferir que os representantes dos stakeholders locais têm pouco conhecimento das políticas previstas e em vigor para o desenvolvimento turístico local, não sendo consensual entre eles a opinião sobre a existência ou não de uma política estratégica especifica para São Miguel. Alguns alegam que a política do turismo tem sido pensada e planeada na globalidade do arquipélago, e que a Ilha de São Miguel constituiu-se como uma parte do todo, não sendo realizada de forma individualizada, nem tendo em consideração as características de cada ilha.

“O Turismo tem sido vendido na sua generalidade, como um todo. Não tem sido feito para São Miguel.”(E4)

"Não penso que haja uma política de turismo para a ilha (...) acho sim que tem existido uma serie de coisas que são mais o resultado da atuação dos agentes económicos, do que propriamente de uma política estratégica para a ilha." (E7)

De acordo com estes dados podemos concluir que o planeamento turístico na RAA segue a metodologia de cariz mais convencional, que segundo Gunn (1993) baseia-se num processo em que os stakeholders são consultados de forma minimalista e muito orientado para a concretização do plano, sendo o seu sucesso medido pela concretização dos objetivos contidos no mesmo.

Por fim, apesar da falta de concordância relativamente à existência de uma política estratégica específica para São Miguel, foi elencando pelos stakeholders um conjunto de medidas que esta política deveria contemplar, direcionadas para: uma avaliação adequada das repercussões da liberalização do espaço aéreo; uma aposta em mercados mais competitivos e geograficamente mais próximos (nomeadamente o alemão, espanhol e italiano); maior enfoque nas áreas protegidas, conservação da natureza, mar e recursos marinhos; mais dinamização dos centros das cidades, do comércio e serviços tradicionais e uma maior aposta na divulgação da gastronomia e dos produtos locais.

Estas sugestões vão parcialmente ao encontro ao Plano Estratégico e de Marketing do Turismo dos Açores (IPDT, 2016), que defende uma aposta em produtos estratégicos assentes no desenvolvimento do turismo de natureza.

\section{Conclusão}

O turismo em São Miguel apresentou um crescimento considerável desde a liberalização do espaço aéreo, razão por que importava conhecer a perspetiva de alguns stakeholders institucionais sobre este recente fenómeno.

O primeiro objetivo de investigação consistiu em apurar os principais impactos percecionados. Até ao momento, o crescimento turístico é visto como benéfico, principalmente pelos aspetos económicos, devido à dinamização da economia local e à geração de emprego num cenário de elevados níveis de desemprego. Outros impactos são identificados, quer ambientalmente (maior consciência para a necessidade de preservar o meio ambiente, acúmulo de resíduos e degradação de trilhos pedestres e a existência de uma sensação de "crowding" em áreas ambientalmente sensíveis) quer socio-cultural (diversificação da oferta cultural, dinamização do artesanato, interculturalidade, recuperação da identidade açoriana, orgulho pela cultura e pelas tradições locais, alguns problemas localizados sobretudo no centro urbano, nomeadamente congestionado, acumulação de lixo e ruído, bem como alguma mudança no estilo de vida familiar e social), não sendo, contudo, ainda muito significativos. 
Esta predominância da perceção dos impactos (económicos) positivos face aos negativos, dever-se-á ao facto do sector estar numa fase de crescimento inicial, que de acordo com a Modelo do Ciclo de Vida do Turismo (Butler, 2006), poderá enquadrar-se na $2^{\text {a }}$ fase "Envolvimento". Esta fase é caracterizada pela descoberta e adaptação, por parte do destino turístico e da comunidade local, tentado suprir as necessidades da nova realidade de crescimento turístico e corresponder às expetativas dos visitantes, onde a população local começa a olhar para o turismo como uma atividade benéfica, sobretudo em termos económicos.

O segundo objetivo de investigação consistia em identificar as dimensões potenciadoras da competitividade da ilha enquanto destino turístico. De acordo com o modelo desenvolvido por Ritchie e Crouch (2000, 2003), foram valorizados os recursos centrais e atrações (a cultura, o clima, a qualidade ambiental, a gastronomia, a diversidade paisagística, o termalismo e a biodiversidade terrestre e marinha) e os determinantes qualitativos (segurança e a tranquilidade). Foram identificadas como fraquezas: o planeamento e desenvolvimento do destino (desconhecimento da capacidade de carga e falta de liderança política); e a gestão do destino onde é evidenciada a falta de formação dos profissionais e a dificuldade em atrair investidores externos.

O terceiro objetivo de investigação procurava conhecer o tipo de participação na gestão e planeamento da atividade. Foi possível apurar que, apesar dos entrevistados atribuírem importância à necessidade da participação ativa de todos os agentes locais no processo de decisão, este envolvimento é realizado de forma bastante residual, mais consentâneo com um processo de participação passiva. A situação foi justificada pela dificuldade dos stakeholders e decisores políticos trabalharem em equipa, e na falta de motivação e interesse por parte das entidades responsáveis em promover e incentivar a participação dos diversos agentes locais.

Estes são fatores que merecem reflexão por parte dos planeadores políticos.

\section{Bibliografia}

Almeida-García, F., Peláez-Fernández, M. Á., Balbuena-Vazquez, A., \& Cortes-Macias, R. 2016. "Residents' perceptions of tourism development in Benalmádena (Spain)". Tourism Management, 54, 259-274.

Andriotis, K. 2001. "Tourism Planning and Development in Crete: Recent Tourism Policies and their Efficacy". International Journal of Sustainable Tourism, 9(4), 298-316.

Araujo, L. \& Bramwell, B. 1999. "Stakeholder assessment and collaborative tourism planning: the case of Brazil's Costa Dourada Project". Journal of Sustainable Tourism, 7 (3-4), 356-378.

Arnstein, S. R. 1969. "A ladder of citizen participation". Journal of the American Institute of planners, 35(4), 216-224.

Bramwell, B. \& Lane, B. 2000. Tourism collaboration and partnerships: politics, practice and sustainability. Clevedon: Channel View.

Butler, R. 2006. "The Tourism Area Life Cycle. Applications and Modifications". Vol.1. Aspects of Tourism 28. Channel View Publications.

Caffyn, A. \& Jobbins, G. 2003. "Governance capacity and stakeholder interactions in the development and management of coastal tourism: Examples from Morocco and Tunisia". Journal of Sustainable Tourism, 11 (2-3), 224-245.

Calado, H., Quintela, A. \& Porteiro, J. 2007. "Integrated Coastal Zone Management Strategies on Small Islands". Journal of Coastal Research, 50, 125-129.

Campón-Cerro, A., Folgado-Fernández, J., \& Hernández-Mogollón, J. 2017. "Rural destination development based on olive oil tourism: The impact of residents' community attachment and quality of life on their support for tourism development". Sustainability, 9(9), 1-16.

Carlsen, J. \& Butler, R. (Eds.) 2011. Island tourism: Sustainable perspectives. Wallingford: CABI.

Céspedes-Lorente, J., Burgos-Jiménez, J. \& Alvarez-Gil, M.J. 2003. "Stakeholders' environmental influence. An empirical analysis in the Spanish hotel industry Scandinavian". Journal of Management, 19, 333-358.

Chang, K., Chien, H., Cheng, H., \& Chen, H. I. 2018. "The Impacts of Tourism Development in Rural Indigenous Destinations: An Investigation of the Local Residents' Perception Using Choice Modeling". Sustainability, 10(12), 4766.

Croes, R. 2006. "A paradigm shift to a new strategy for small island economies: Embracing demand side economics for value enhancement and long term economic stability". Tourism Management, 27 (3), 453-465. 
Crouch, G. 2007. Modelling destination competitiveness. CRC for sustainable tourism. Queensland, Australia.

Crouch, G. \& Ritchie, J. 1999. "Tourism, competitiveness, and societal prosperity". Journal of Business Research, 44,137-152.

Dogan, H. 1989. "Forms of adjustment: sociocultural impacts of tourism". Annals of Tourism Research. 16(2), 216-236.

Eusébio, C., Vieira, A. L., \& Lima, S. 2018. "Place attachment, host-tourist interactions, and residents' attitudes towards tourism development: the case of Boa Vista Island in Cape Verde". Journal of Sustainable Tourism, 26(6), 890-909.

Flick, U. 2014. An Introduction to Qualitative Research, Londres: SAGE Publications.

Freeman, R. 1984. Strategic Management: A stakeholder approach. Boston: Pitman.

Goffi, G. 2013. "A Model of Tourism Destinations Competitiveness: The case of the Italian Destinations of Excellence". Anuario Turismo y Sociedad, XIV,121-147.

Gunn, C. 1993. Tourism, Planning: Basics Concepts, Cases. Levittown: Taylor \& Francis.

Guo, Y., Kim, S. \& Chen, Y. 2014. "Shangai Residents' Perceptions of Tourism Impacts and Quality of Life". Journal of China Tourism Research, 10 (2), 142-164.

Haralambopoulous, N. \& Pizam, A. 1996. "Perceived impacts of tourism: The case of Samos". Annals of Tourism Research 23 (3), 503-526.

Harun, R., Chiciudean, G., Sirwan, K., Arion, F., \& Muresan, I. 2018. "Attitudes and Perceptions of the Local Community towards Sustainable Tourism Development in Kurdistan Regional Government, Iraq". Sustainability, 10(9), 1-13.

Instituto de Turismo (IPDT)/ Governo Regional dos Açores 2016. Plano Estratégico e de Marketing do Turismo dos Açores. Disponível online em http://www.azores.gov.pt/PortalAzoresgov/external/portal/ misc/PEM_ACORES2.pdf

Ivanov, S. \& Webster, C. 2007. "Measuring the impact of tourism on economic growth". Tourism Economics, 13 (3), 379-388.

Kim, K. 2002. The effects of tourism impacts upon quality of life of residents in the community. $\mathrm{PhD}$ Dissertation. Faculty of the Virginia Polytechnic Institute and State University. Disponível online [http://scholar.lib.vt.edu/theses/available/etd-12062002-123337/unrestricted/ Title_and_Text.pdf] consultado em 31/03/2015.

Liu, X., \& Li, J. 2018. "Host perceptions of tourism impact and stage of destination development in a developing country". Sustainability, 10(7), 1-15.

Liu, J. \& Var, T. 1986. "Resident attitudes toward tourism impacts in Hawaii". Annals of Tourism Research 13 (2), 193-214.

Mason, P. 2003. Tourism Impacts, Planning and Management. Oxford: Butterworth-Heinemann.

McDowall, S. \& Choi, Y. 2010. “A Comparative Analysis of Thailand Residents' Perception of Tourism's Impacts”, Journal of Quality Assurance in Hospitality \& Tourism, 11 (1), 36-55.

Moniz, A. 2006. A sustentabilidade do turismo em ilhas de pequena dimensão: o caso dos Açores. Doutoramento em Ciências Económicas e Empresariais na especialidade de Desenvolvimento Económico e Social e Economia Pública. Ponta Delgada: Universidade dos Açores

Muresan, I., Oroian, C., Harun, R., Arion, F., Porutiu, A., Chiciudean, G., Todea, A, \& Lile, R. 2016. "Local residents' attitude toward sustainable rural tourism development". Sustainability, 8(1), 1-14.

Observatório do Turismo dos Açores 2008. A qualidade do destino açores na perspetiva dos turistas: principais conclusões. Observatório Regional do Turismo. Disponível online em: http://www.observatorioturismoacores.com/data/1265043369.pdf.

Oliveira e Sá, D. 2014. Competitividade de destinos turísticos no âmbito da Gestão. O caso do Porto. Dissertação de Mestrado. Universidade de Aveiro.

Özel, Ç. H., \& Kozak, N. 2017. "An exploratory study of resident perceptions toward the tourism industry in Cappadocia: a Social Exchange Theory approach". Asia Pacific Journal of Tourism Research, 22(3), 284-300.

Quivy, R. \& Campenhoudt, L. 1995. Manual de Investigação em Ciências Sociais. Lisboa: Gradiva.

Rasoolimanesh, M., Jaafar, M., \& Ramayah, T. 2017. "Factors Influencing Residents' Perceptions toward Tourism Development: Differences across Rural and Urban World Heritage Sites”. Journal of Travel Research, 56(6), 760-775.

Rietbergen, S. Hammond, T. Sayegh, C., Hesselink F. \& Mooney, K. 2007. Island voices - island choices: Developing strategies for living with rapid ecosystem change in small islands. Gland, Switzerland: IUCN. 
Ritchie, J. \& Crouch, G. 2000. "The competitive destination: a sustainable perspective", Tourism Management, 21, 1-7.

Ritchie, J. \& Crouch, G. 2003. The competitive destination: a sustainable tourism perspective. Wallingford: CABI.

Sánchez-Cañizares, S. M., Castillo Canalejo, A. M., \& Núñez Tabales, J. M. 2016. "Stakeholders' perceptions of tourism development in Cape Verde, Africa". Current Issues in Tourism, 19(10), 966-980.

Santos, C., Couto, G., Pimentel, P.M. \& Vieira, J.C. 2012. "Quality of the Azores destination in the perspective of tourists", Tourism and Hospitality Research 12 (1), 32 - 42.

Sautter, E. \& Leisen, B. 1999. "Management stakeholders: a tourism planning model". Annals of Tourism Research, 26 (2), 312-328.

Scheyvens, R. \& Momsen, J. 2008. "Tourism in Small Island States: From Vulnerability to Strengths". Journal of Sustainable Tourism, 16 (5), 491-510.

Sharpley, R. 2012. "Island Tourism or Tourism on Islands". Tourism Recreation Research, 37(2), 167-172.

Sharpley, R. 2014. "Host perceptions of tourism: A review of the research". Tourism Management, 42, 37-49.

Sheldon, P. 2005. The Challenges to Sustainability in Tourism Islands. Ocasional Paper 2005-01. University of Hawai, Manoa. Disponível online em https://www.researchgate.net/publication/237594447_The_Challenges_to_Sustainability_in_Island_Tourism

Silva, F. \& Umbelino, J. (Coord.) 2017. Planeamento e Desenvolvimento Turistico. Lisboa: Lidel.

Silva, F. 2013. Turismo na natureza como base do desenvolvimento turístico responsável nos Açores. Doutoramento em Geografia. Universidade de Lisboa, Instituto de Geografia e Ordenamento do Território.

Simão, J., \& Môsso, A. 2013. "Residents' perceptions towards tourism development: the case of Sal Island". International Journal of Development Issues, 12(2), 140-157.

Simão, J. N., \& Partidário, M. D. R. 2012. "How does tourism planning contribute to sustainable development?". Sustainable Development, 20(6), 372-385.

Swarbrooke, J. 1999. Sustainable Tourism Management. Londres: CABI Publishing.

Timothy, D. 1998. "Cooperative tourism planning in a developing destination". Journal of Sustainable Tourism, 6 (1), 52-68.

Tosun, C. 2000. "Limits to community participation in the tourism development process in developing countries". Tourism Management, 21, 613-633.

Tufte, T. \& Mefalopulos, P. 2009. Participatory Communication. A Practical Guide. World Bank Working Paper $\mathrm{n}^{\circ}$ 170. Washington, D.C. Disponivel online: http://documents.worldbank.org/curated/ en/682081468166154717/pdf/499270PUB0comm101Official0Use0Only1.pdf

Turismo de Portugal I.P. 2017. Estratégia Turismo 2027. Turismo de Portugal I.P.

Wall, G. \& Mathieson, A. 2006. Tourism: Change, Impacts, Opportunities. Essex: Pearson.

Woosnam, K. M., Draper, J., Jiang, J. K., Aleshinloye, K. D., \& Erul, E. 2018. "Applying self-perception theory to explain residents' attitudes about tourism development through travel histories". Tourism Management, 64, 357-368.

Wright, D., \& Sharpley, R. 2018. Local community perceptions of disaster tourism: the case of L'Aquila, Italy. Current Issues in Tourism, 21(14), 1569-1585.

WTO 1993. Sustainable tourism development: guide for local planners. Madrid: WTO.

WTTC, WTO \& The Earth Council 1993. Agenda 21 for the Travel and Tourism Industry-towards environmentally sustainable development. London: WTTC, WTO and the Earth Council.

WTTC 2017. Travel and Tourism. Economic Impact 2017 World. United Kingdon: WTTC.

Zhu, H., Liu, J., Wei, Z., Li, W., \& Wang, L. 2017. "Residents' attitudes towards sustainable tourism development in a historical-cultural village: Influence of perceived impacts, sense of place and tourism development potential”. Sustainability, 9(1), 1-15.

Recibido:

$06 / 02 / 2018$

Reenviado:

$06 / 03 / 2019$

Aceptado:

$04 / 04 / 2019$

Sometido a evaluación por pares anónimos 